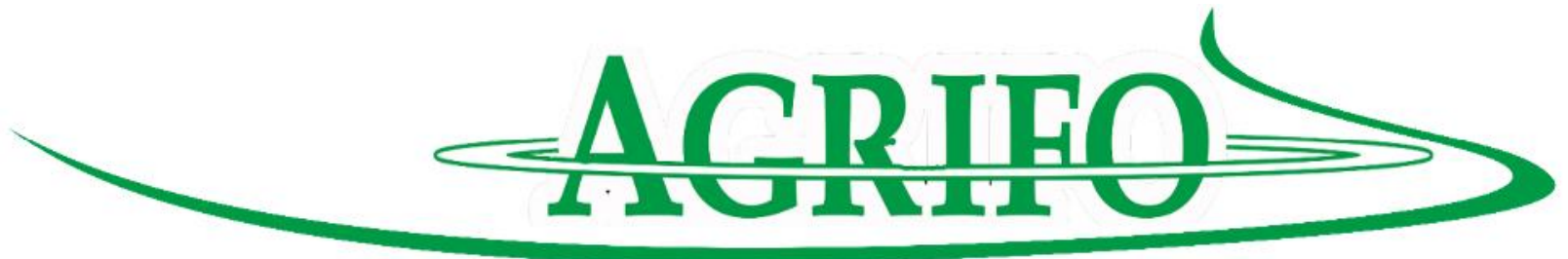

\title{
PROSPEK PENGEMBANGAN USAHA TANI MELON KECAMATAN MUARA BATU DAN DEWANTARA KABUPATEN ACEH UTARA
}

\author{
Suwardi $^{1}$, Zuriani $^{2}$ dan Murdani ${ }^{2}$ \\ ${ }^{1}$ Program Studi Agribisnis Fakultas Pertanian \\ ${ }^{3}$ Staff Pengajar Program Studi Agribisnis Universitas Malikussaleh
}

\begin{abstract}
ABSTRAK
Penelitian ini bertujuan untuk mengetahui prospek pengembangan usahatani melon ditinjau dari analisis usahatani di Kecamatan Muara Batu dan Dewantara serta prospek pengembangan usahatani melon di Kecamatan Muara Batu dan Dewantara ditinjau dari segi kekuatan, kelemahan, peluang dan ancaman. Pengumpulan data dilakukan melalui wawancara, observasi dan dokumentasi. Jumlah sampel sebanyak 16 petani. Data dianalisis menggunakan analisis kuantitatif dan deskriptif.

Hasil penelitian menunjukkan bahwa besar pendapatan petani dari usahatani melon di Kecamatan Muara Batu dan Dewantara adalah Rp. 38.746.893/Ha serta biaya produksi dikeluarkan sebesar Rp. 18.043.842/Ha, dan menghasilkan keuntungan sebesar Rp. 20.703.051. Prospek pengembangan usahatani melon di Kecamatan Muara Batu dan Dewantara ditinjau dari segi kekuatan usahatani melon memiliki luas lahan yang cukup serta teknik budidaya, kelemahan dimana belum adanya upaya penanggulangan hama, peluang dimana melon sudah dikenal oleh masyarakat serta adanya ancaman berupa tingginya curah hujan pada waktu tertentu dan pemasaran yang belum stabil.

Kata Kunci: Prospek Pengembangan, Usahatani Melon

\section{PENDAHULUAN}

Usahatani melon adalah jenis usahatani yang perlu mendapat perhatian dalam pengembangannya. Hal ini didasarkan pada kenyataan bahwa produk melon sangat digemari

masyarakat baik sebagai buah segar maupun dalam bentuk juice, bahkan sebagai bahan baku industri minuman. Selain itu, harga buah melon yang relatif tinggi dibanding
\end{abstract}


komoditas sejenis merupakan peluang besar untuk peningkatan pendapatan dan kesejahteraan petani atau pengusaha usahatani melon (Rukmana, 2000). Kecamatan Muara Batu dan Dewantara merupakan daerah produksi melon di Aceh Utara. Jumlah produksi melon di Kecamatan Muara Batu tahun 2014 dengan 43,90 Ton, sedangkan di Dewantara terjadi pada tahun 2014 sebanyak 31,2 ton.

Produksi melon bisa memberikan keuntungan yang besar bagi petani (Tjahjadi, 1987). Budidaya melon di Kecamatan Muara Batu dan Dewantara diusahakan pada lahan 7,6 $\mathrm{Ha}$ dan telah mengalami lima kali panen, namun produksi melon cenderung menurun. Usahatani melon sangat bergantung pada cuaca, pada bulan September-Desember. petani tidak berani melakukan budidaya, karena tanaman melon sangat rentan terhadap penyakit pada musim hujan. Sebagian besar petani melon menggunakan air sumur atau pompa air untuk memenuhi kebutuhan air, karena lahan yang ditanami melon adalah lahan kering. Dengan demikian kebutuhan biaya yang diperlukan juga tinggi dan dapat mengurangi keuntungan petani di Kabupaten Aceh Utara yang disebabkan oleh tidak stabilnya harga melon di pasaran. Harga melon di Provinsi Aceh selama tahun 20102014 dapat dilihat pada Tabel 2 berikut.

Tabel 2. Harga Melon di Provinsi Aceh dan Kabupaten Aceh Utara, 2010-2014

\begin{tabular}{ccrc}
\hline No & Tahun & Provinsi Aceh & Aceh Utara \\
\hline 1 & 2010 & 8.000 & 7.000 \\
\hline 2 & 2011 & 8.000 & 7.000 \\
\hline 3 & 2012 & 6.500 & 5.000 \\
\hline 4 & 2013 & 9.000 & 8.000 \\
\hline 5 & 2014 & 10.000 & 9.000
\end{tabular}

Sumber: Pasar Lambaro dan Keude Krueng Geukuh, 2014 
Tujuan dalam penelitian ini adalah:

1. Untuk mengetahui prospek pengembangan usahatani melon ditinjau dari analisis usahatani di Kecamatan Muara Batu dan Dewantara.

2. Untuk mengetahui prospek pengembangan usahatani melon di Kecamatan Muara Batu dan Dewantara ditinjau dari segi kekuatan, kelemahan, peluang dan ancaman.

\section{METODE PENELITIAN}

Penelitian akan dilakukan di Kecamatan Muara Batu dan Dewantara. Penentuan lokasi penelitian ini dilakukan dengan sengaja (Purposive) karena di daerah tersebut terdapat petani yang melakukan usahatani melon. Ruang lingkup penelitian ini terbatas pada analisis usahatani dengan prospek pengembangan usahatani melon dan analisis peluang, ancaman, kekuatan dan hambatan.

Metode yang digunakan dalam penarikan sampel ini adalah sampling jenuh atau sensus. Pengertian dari sampling jenuh atau sensus menurut Sugiyono (2008) adalah "Sampling jenuh atau sensus adalah teknik penentuan sampel bila semua anggota populasi digunakan sebagai sampel." Berikut data tentang populasis dan sampel penelitian.

\begin{tabular}{clc}
\hline No & Lokasi Sampel & Populasi dan sampel \\
\hline 1 & Keude Mane & 4 \\
\hline 2 & Cot Seurani & 3 \\
\hline 3 & Dakuta & 2 \\
\hline 4 & Pante Gurah & 5 \\
\hline 5 & Lancang Barat & 2 \\
\hline 6 & Paloh Lada & 1 \\
\hline & Jumlah & $\mathbf{1 6}$
\end{tabular}

Sumber: BPP Muara Batu dan Dewantara, 2015

Analisis data dalam penelitian ini yaitu analisis kuantitatif dan dapat dilakukan dengan dua metode kualitatif. Berikut penjelasan untuk 
masing-masing metode tersebut $\pi$ : Keuntungan

(Moleong, 1999).

\section{Analisis Kuantitatif}

TR : Penerimaan

Analisis Biaya

Untuk menghitung biaya yang dikeluarkan digunakan rumus sebagai berikut:

$\mathrm{TC}=\mathrm{FC}+\mathrm{VC}$

Keterangan

TC : Total Biaya

FC : Biaya Tetap

VC : Biaya Variabel

Analisis Penerimaan

Untuk menghitung penerimaan digunakan rumus sebagai berikut:

$\mathrm{TR}=\mathrm{Py} \cdot \mathrm{y}$

Keterangan

TR : Penerimaan

Py : Harga jual

Y : Produksi

Analisis Keuntungan

Untuk menghitung keuntungan digunakan rumus sebagai berikut:

$\Pi=$ TR-TC

TC : Biaya

Keuntungan diperoleh setelah dihitung selisih biaya dengan pendapatan kotor. Pendapatan kotor diperoleh dari penjualan hasil panen melon/Ha. Sedangkan biaya dihitung dari biaya pengolahan lahan hingga panen untuk memastikan bahwa usahatani melon menguntungkan dan memiliki prospek yang bagus untuk dikembangkan, maka dilakukan analisis $\mathrm{B} / \mathrm{C}$ ratio dengan rumus sebagai berikut:

Keuntungan

B $/ \mathrm{C}$ Rasio =

Total biaya

Kriteria

B/C Ratio > 0 : Menguntungkan

B/C Ratio < 0 : Tidak

Menguntungkan

$\mathrm{B} / \mathrm{C}$ Ratio $=0:$ Impas

Analisis Kualitatif atau Deskriptif

Analisis kualitatif untuk melihat gambaran prospek pengembangan 
dinilai melalui analisis SWOT (Strenght, Weakness, Opportunities,

Threat) dilihat berdasarkan kekuatan, kelemahan, peluang dan ancaman.

\section{HASIL DAN PEMBAHASAN}

\section{Analisis Biaya Usahatani}

\section{Biaya Tetap}

Biaya tetap ( fixed cost) merupakan biaya yang besarnya tidak tergantung pada jumlah produksi. Biaya tetap dalam penelitian ini adalah biaya

Tabel 5. Biaya Penyusutan Rata-rata Peralatan Usahatani melon Per Hektar di Kecamatan Muara Batu dan Dewantara

\begin{tabular}{lllccc}
\hline No & $\begin{array}{c}\text { Nama } \\
\text { Peralatan }\end{array}$ & Satuan & $\begin{array}{c}\text { Jumlah } \\
(\text { Unit })\end{array}$ & $\begin{array}{c}\text { Harga Beli } \\
(\mathbf{R p})\end{array}$ & $\begin{array}{c}\text { Nilai Penyusutan } \\
(\text { Rp/Ha/tahun) }\end{array}$ \\
\hline 1 & Cangkul & Unit & 5 & 80.000 & 100.351 \\
\hline 2 & Parang & Unit & 5 & 30.000 & 100.000 \\
\hline 3 & $\begin{array}{l}\text { Kereta } \\
\text { Sorong }\end{array}$ & Unit & 3 & 350.000 & 153.289 \\
\hline 4 & Alat Semprot & Unit & 3 & 360.000 & 269.939 \\
\hline & Jumlah & & & & 623.579
\end{tabular}

Sumber: Data Primer diolah, 2016

Sedangkan biaya tetap tetap produksi yang dikeluarkan merupakan penjumlahan sewa lahan dengan penyusutan. Berikut biaya penyusutan peralatan dan biaya sewa lahan.

Peralatan yang digunakan dalam usahatani melon adalah cangkul, parang, kereta sorong dan alat semprot. Harga awal dan nilai penyusutan adalah rata-rata dari harga awal dan nilai penyusutan per unit peralatan yang digunakan dalam usahatani melon dapat dilihat pada Tabel 5 berikut.

$\begin{aligned} \text { Sedangkan biaya tetap } & \text { tetap produksi yang dikeluarkan } \\ \text { merupakan penjumlahan sewa lahan } & \text { petani melon di Kecamatan Muara } \\ \text { dengan penyusutan. Berikut biaya } & \text { Batu dan Kecamatan Dewantara. }\end{aligned}$


Tabel 6. Biaya Tetap Produksi Melon Per Hektar di Kecamatan Muara Batu dan Dewantara

\begin{tabular}{|c|l|r|}
\hline No. & \multicolumn{1}{|c|}{ Biaya Tetap } & Jumlah (Rupiah/Tahun) \\
\hline 1 & Sewa Lahan & 950.000 \\
\hline 2 & Biaya penyusutan & 623.579 \\
\hline & Jumlah & 1.573 .579 \\
\hline
\end{tabular}

Sumber: Hasil Penelitian, 2016 (Data diolah)

Berdasarkan Tabel 6 di atas dapat dicermati bahwa biaya tetap produksi melon di Kecamatan Muara Batu dan Dewantara berjumlah Rp. 1.573.579. Biaya tetap ini meliputi sewa lahan dan biaya penyusutan.

\section{Biaya Variabel}

Biaya variabel merupakan biaya yang dikeluarkan untuk penyediaan sarana produksi, dan tenaga kerja. Yang rincian pengeluarannya adalah seperti pada Tabel7.

Tabel 7. Rincian Biaya Variabel Usahatani Melon Per Hektar Per Tahun di Kecamatan Muara Batu dan Dewantara

\begin{tabular}{llllr}
\hline No & Uraian & Satuan & Jumlah & \multicolumn{1}{c}{ Jumlah Biaya } \\
\hline 1 & Biaya Tenaga Kerja & Rp/orang & 7,33 & 2.070 .263 \\
\hline 2 & Biaya Sarana Produksi & & & \\
& a. Pupuk NPK & Rp/Ha & $250 \mathrm{Kg}$ & 3.000 .000 \\
& b. Pestisida & Rp/Ha & $500 \mathrm{Liter}$ & 7.500 .000 \\
& c. Benih & Rp/Bungkus & 15 Bungkus & 3.900 .000 \\
\hline Total & & & 16.470 .263 \\
\hline
\end{tabular}

\section{Biaya Produksi}

Biaya produksi disini adalah penyusutan peralatan dan biaya variable.

penjumlahan biaya total daripada 
Tabel 8. Biaya Produksi Melon di Kecamatan Muara Batu dan Dewantara

\begin{tabular}{lll}
\hline No & Uraian & Jumlah $(\mathbf{R p )}$ \\
\hline 1 & Biaya Tetap & 1.573 .579 \\
\hline 2 & Biaya Variabel & 16.470 .263 \\
\hline & Total & 18.043 .842 \\
\hline
\end{tabular}

Analisis Penerimaan

Rata-rata produksi melon yang dihasilkan petani mencapai $4661 \mathrm{Kg} / \mathrm{Ha}$. Harga jual rata-rata melon pada saat dilakukan penelitian adalah Rp. 8313 dan diperoleh nilai produksi atau total penerimaan sebesar Rp. 38.746.893/Ha, biaya produksi Rp. 18.043.842/Ha. Jumlah Produksi, harga jual dan modal, penerimaan dan keuntungan usahatani melon per hektar dapat dilihat pada Tabel 9 berikut:

Tabel 9. Produksi, Harga Jual, Modal, Penerimaan dan Keuntungan Usahatani melon Per Hektar di Kecamatan Muara Batu dan Dewantara

\begin{tabular}{cllr}
\hline No & \multicolumn{1}{c}{ Uraian } & Satuan & \multicolumn{2}{c}{ Jumlah (Rp) } \\
\hline 1 & Jumlah Produksi & $\mathrm{Kg} / \mathrm{Ha}$ & 4.661 \\
\hline 2 & Harga Jual Rata-rata & $\mathrm{Rp} / \mathrm{Kg}$ & 8.313 \\
\hline 3 & Biaya Produksi & $\mathrm{Rp} / \mathrm{Ha}$ & 18.043 .842 \\
\hline 4 & Penerimaan & $\mathrm{Rp} / \mathrm{Ha}$ & 38.746 .893 \\
\hline 5 & Keuntungan & $\mathrm{Rp} / \mathrm{Ha}$ & 20.703 .051
\end{tabular}

Sumber: Data Primer diolah, 2016

Produksi yang dimaksud adalah jumlah fisik yang dihasilkan dihasilkan dalam usahatani melon. Pengelolaan usahatani melon yang baik dan penggunaannya sarana produksi yang sesuai kebutuhan akan meningkatkan produksi melon sehangga pendapatan yang diperoleh akan lebih baik lagi dan kesejahteraan petani pun meningkat.

\section{B/C Ratio}

Nilai B/C ratio dapat digunakan untuk mengetahui kelayakan suatu usaha ditinjau dari proporsi besarnya biaya produksi 
yang dikeluarkan terhadap Nilai B/C ratio pada usaha melon keuntungan yang akan diperoleh. dapat ditunjukkan pada Tabel berikut:

Tabel 10. Analisis B/C Ratio Usahatani melon di Kecamatan Muara Batu dan Dewantara

\begin{tabular}{|c|l|r|}
\hline No & \multicolumn{1}{|c|}{ Uraian } & \multicolumn{1}{|c|}{ Nilai (Rp) } \\
\hline 1 & Keuntungan & 20.703 .051 \\
\hline 2 & Biaya Produksi & 18.043 .842 \\
\hline $\mathbf{3}$ & B/C Ratio & $\mathbf{1 , 1 5}$ \\
\hline
\end{tabular}

Sumber : Hasil Penelitian (diolah), 2016

Pada Tabel 10 diketahui yang diperoleh lebih besar dari modal bahwa perbandingan antara yang dikeluarkan. Setiap biaya keuntungan dengan biaya produksi produksi yang dikeluarkan sebesar adalah sebesar 1.15. Hal tersebut Rp. 18.043.842 akan menghasilkan menunjukkan bahwa usaha tersebut keuntungan sebesar Rp. 20.703.051. nilai $\mathrm{B} / \mathrm{C}$ rationya lebih besar dari nol sehingga usaha tersebut jika di usahakan akan mendatangkan keuntungan. Oleh karena itu, usaha melon layak untuk dikembangkan. Hal ini menunjukkan setiap nilai Rupiah yang dikeluarkan dalam produksi akan memberikan manfaat sejumlah nilai keuntungan yang diperoleh. Nilai B/C Ratio sebesar Analisis SWOT Usahatani Melon

Setiap usaha tidak selamanya berjalan mulus. Begitu juga dengan usaha melon. Dalam pengusahaannya, usahatani melon memiliki kekuatan, kelemahan, peluang dan ancaman yang terpetakan melalui penelitian. Analisis tersebut dapat dilihat pada Tabel 11 berikut:

1.15 berarti besarnya keuntungan 
Tabel 11. Analisis SWOT Usahatani melon di Kecamatan Muara Batu dan Dewantara

\section{Kekuatan}

- Luas lahan yang ditanami masih mencukupi/tersedia

- Sarana produksi (pupuk, pestisida, bibit) mudah diperoleh di pasar

- kualitas melon yang diproduksi (seperti tingkat kemanisan, kerenyahan) yang dihasilkan telah memenuhi standar

\section{Kelemahan}

lahan belum diolah dengan benar belum ada upaya untuk menanggulangi serangan hama hasil panen belum dapat diolah menjadi produk makanan tertentu seperti sirup, dodol, dll

\section{Peluang}

- saat ini melon sudah dikenal oleh masyarakat

- masyarakat suka mengkonsumsi buah melon sebagai nutrisi

- setiap orang menyukai buah melon

- adanya Riset pertanian membantu petani untuk mengembangkan usahatani melon

- adanya Publikasi media tentang budidaya melon sangat mendukung usahatani melon

\section{Ancaman}

Masih terdapat benih palsu

Curah hujan tinggi, menyebabkan tanaman membusuk

Serangan hama menyebabkan banyak buah yang tidak dapat dipanen

Harga melon kurang stabil

Masih adanya Pasokan melon dari Sumatera Utara

dukungan Pemerintah terhadap petani melon masih rendah

\section{KESIMPULAN}

1. Besar pendapatan petani dari usahatani melon di Kecamatan Muara Batu dan Dewantara adalah Rp. 38.746.893/Ha.

2. Prospek pengembangan usahatani melon di Kecamatan Muara Batu dan Dewantara ditinjau dari segi kekuatan usahatani melon memiliki luas lahan yang cukup serta teknik budidaya, kelemahan dimana belum adanya upaya penanggulangan hama, peluang dimana melon sudah dikenal oleh 
masyarakat serta adanya ancaman berupa tingginya curah hujan pada waktu tertentu dan pemasaran yang belum stabil.

\section{2}

variabel secara lebih mendalam agar kondisi agribisnis usahatani melon sepenuhnya bisa terpetakan.

\section{DAFTAR PUSTAKA}

Moleong, L. J. (1999). Metodologi penelitian. Bandung: $P T$. Remaja Rosda Karya.

Rukmana, R. (2000). Usaha Tani Jahe. Kanisius.

Sugiyono, D. (2008). Metode Penelitian Bisnis. Bandung: Pusat Bahasa Depdiknas.

Tjahjadi, N. (1987). Bertanam melon. Kanisius. 